\title{
JORNALISMO INDEPENDENTE
}

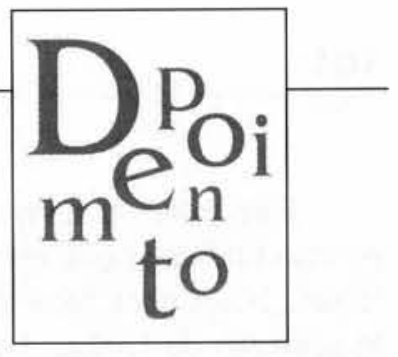

\section{Realidade, Caros Amigos, exemplos do que a imprensa pode significar em compromisso com o jornalismo independente}

Minha experiência no jornalismo começa na Folha quando ainda era Folhas - a da Manhã e a da Noite. Entrei como revisor, num concurso que convidava pelas próprias páginas dos dois jornais, que pertenciam a José Nabantino Ramos, antes que ele perdesse a empresa para o atual proprietário, Otávio Frias. O anúncio dizia: "Você quer ser jornalista?".

Depois de um tempo na revisão, pulei para a reportagem da Folha da Noite. Não parece que foi ontem. Faz muito tempo e muitos empregos e desempregos. Está certo que cada um deles dá uma história, mas seria cansativo, com certeza. Olhem a lista dos empregos: como repórter na Manchete/Fatos \& Fotos, Notícias Populares, 4 Rodas; em Realidade, como editor de texto; como chefe de redação no $O$ Diário, de Ribeirão Preto; em Aqui São Paulo, como editor; como diretor de redação no Jornal da Bahia; no Fantástico, da TV Globo, fui chefe da sucursal paulista; nas rádios Globo/Excelsior e na TV Tupi trabalhei como diretor de jornalismo; na TV Bandeirantes fui diretor do programa 90 Minutos; na TenisEsporte, como editor de texto; na Placar, como chefe de redação; e na revista Globo Rural fui diretor de redação. No desemprego, sempre em turma, com jornalistas amigos (inesquecíveis os que já se foram, como Narciso Kalili, Hamilton Almeida Filho, George Love), fiz $O$ Bondinho, Jornalivro, Revista de Fotografia, O Grilo, Ex-, edições especiais de Guia Rural, da Abril, programas para a TV Record, como Barra Pesada, com Otávio Ribeiro (também ido, saudoso). Montamos empresinhas, a Arte \& Comunicação e a Eco - Equipe de Comunicação, onde realizamos esses dois últimos grupos de trabalhos. E, atualmente, da mesma forma, estou com uma turma de jornalistas e gente amiga com a Editora Casa Amarela, que faz a Caros Amigos e edita também livros (até agora, todos os de Roberto Freire; Capitão Mouro, de Georges Bourdoukan e, mais recentemente, Marighella, de Emiliano José).

O AUTOR

Sérgio de Souza

Jornalista, editor da revista Caros Amigos. 
Para falar da revista Realidade é preciso reafirmar que ela foi uma experiência irrepetível, para lembrar daquele ministro de Collor. Uma conjunção que alguns poderiam atribuir ao zodíaco, tal a felicidade de reunir ao mesmo tempo três fatores culminantes quando se trata de jornalismo: o grande passo de uma editora determinada a fazer vultosos investimentos; um grupo de jornalistas cheios de energia, criatividade e vontade profissional; e o país vivendo a fase inicial de um regime dirigido por militares que haviam tomado o poder por meio de um golpe de Estado. E, ainda, num quadro em que o leitor não tinha alternativas na área de revistas, pois oferecia muito mais que $O$ Cruzeiro e Manchete, duas semanais dadas ao supérfluo e ao ver figuras (fenômeno que, afora os jornais diários, parece estar querendo voltar à moda no Brasil, infelizmente). Então, Realidade foi um achado, tanto que depois da terceira ou quarta edição já alcançava a ti-
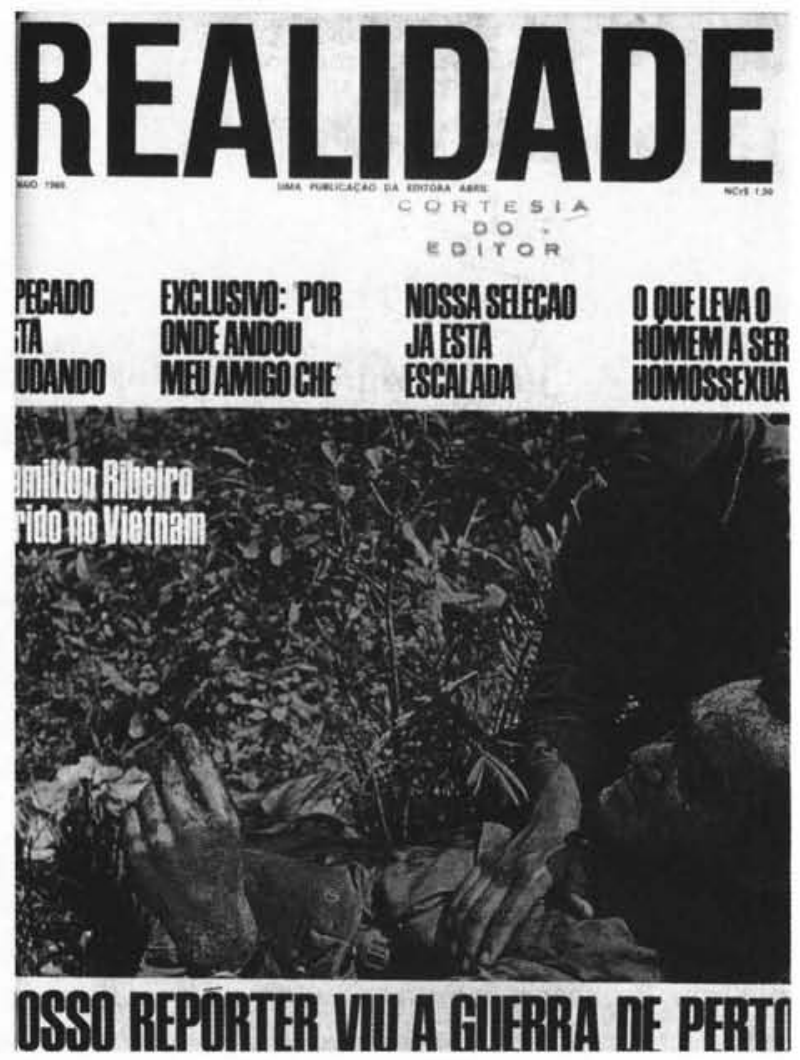

Capa da revista Realidade, maio de 1968.

ragem de 500 mil exemplares. Um achado, principalmente para a Abril, tanto no aspecto financeiro quanto no de imagem da empresa.

Tamanho sucesso propiciou uma avalanche de recursos e de empolgação. A empolgação atingiu o próprio futuro herdeiro da empresa, que participava de tudo, desde as reuniões de pauta à escolha da foto de capa da revista. Os recursos eram os bons salários e a possibilidade de realizar reportagens onde quer que fosse - José Hamilton Ribeiro foi enviado à Guerra do Vietnã, onde acabou por perder a perna ao pisar numa mina, para ficar em um único exemplo.

Além dos meios materiais, a equipe de Realidade gozava de total liberdade na seleção das pautas de cada edição, e pôde assim abordar todos os temas que à época - entre 1966 e 1968, fase áurea da revista - eram tabu na imprensa brasileira, principalmente sexo, religião e esquerda.

Para lembrar uma passagem pessoal, referenciada ao clima que citei, a equipe um dia decidiu que eu me tornaria negro por uns tempos - íamos fazer aqui o que um jornalista americano dissera ter 
feito nos EUA: branco tomara uma droga que sensibiliza a melanina e ficara temporariamente negro, metendose nos bairros e regiões segregadas, para viver na pele o racismo em seu país. Ficaram dúvidas a respeito da honestidade desse jornalista, pois compramos a mesma droga, tomei e fui para Parati, queimar a pele na praia. Não funcionou - adquiri o bronzeado normal de qualquer surfista ou bóia-fria. De volta a São Paulo, continuei o "tratamento", agora submetendo-me a raios ultravioleta. Não só a cor da pele não se alterou como ganhei queimaduras preocupantes nesse aparelho do corpo menos afeito a exposições seja na praia, seja na cidade. Acabei na cadeira de um maquilador de TV e saí para a rua me sentindo um $\mathrm{Al}$ Jonson. Fracasso total.

Em Realidade fazíamos o jornalismo que eu sempre persegui. Prazeroso, conseqüente e formador. Mas que, como esperávamos, incomodava
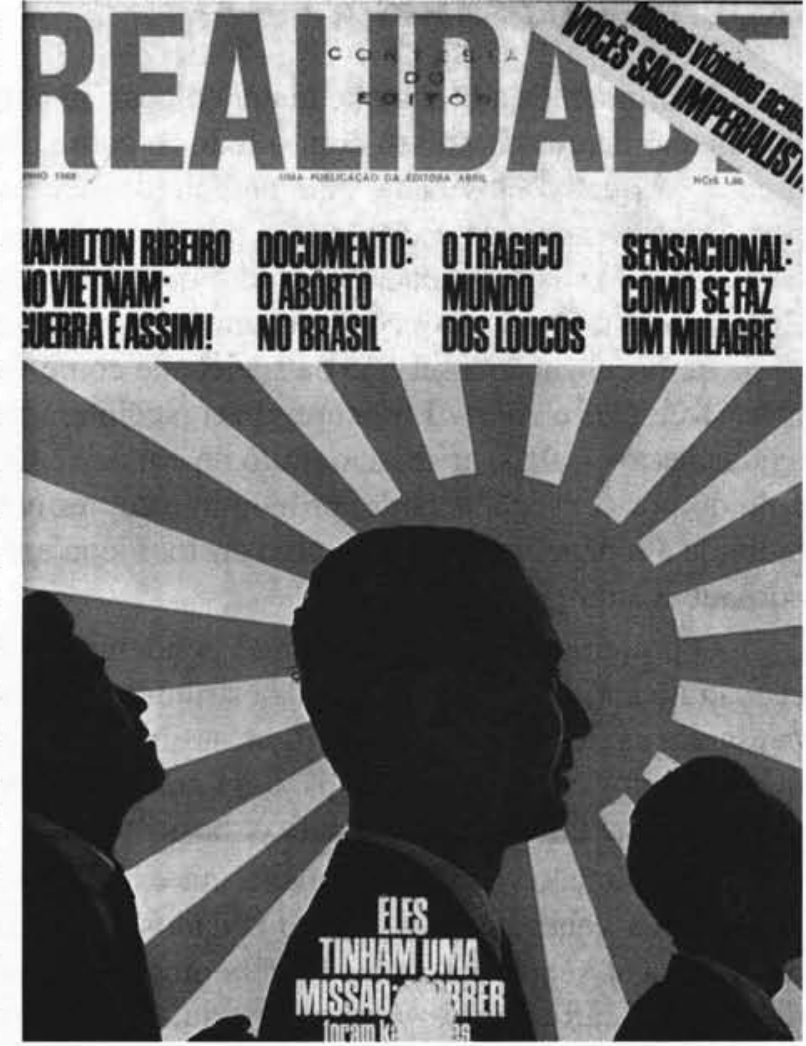

Capa da revista Realidade, junho de 1968. cada vez mais a ditadura militar, que também cada vez mais caminhava para o leito que sempre lhe foi reservado. Já meses antes da decretação do AI-5, começamos a experimentar o dedo da censura interna, vinda da própria diretoria da editora. Em princípio, admitindo a discussão, que sabíamos significar apenas o preâmbulo da implosão da equipe, planejada e logo depois executada. A parte que os econômica e politicamente fortes costumam corriqueiramente chamar de radicais deixou a revista, foi procurar outros caminhos, dos quase nenhum que havia. Fui chamado por Samuel Wainer para o projeto de um tablóide semanal que ele queria lançar, o Idéia Nova. Quase toda a equipe de Realidade, inclusive alguns que não haviam deixado a Abril, empenhou-se no projeto. Liberdade jornalística recuperada, boneco do tablóide pronto, estoura o AI-5. Na mesma noite de 13 de dezembro de 1968, Samuel desaparece e corremos todos a desmontar a redação, improvisada num espaço que ele conseguira no Hotel Apolo, na Boca do Lixo, em São Paulo. Começavam os anos de chumbo. Longos anos, e cheios de histórias envolvendo jornalistas. Mas, essas ficam para outra oportunidade. 


\section{HOJE, EM CAROS AMIGOS}

Continuamos a busca que tentei colocar há pouco, a busca do jornalismo de compromisso com o leitor e com nossa idéia de imprensa, enquanto atividade que nasceu da necessidade, sentida por certos homens, de esclarecer as pessoas sobre o mundo que as cerca, de informar os cidadãos sobre o que as instituições que eles sustentam estão fazendo e como se comportam eticamente. Uma espécie de fiscalização a serviço da sociedade como um todo. No número 1 de Caros Amigos procurei dizer, sucintamente como agora, a que viemos - aliás, era esse o título do editorial. $\mathrm{O}$ formato foi escolhido por conseqüência de, primeiramente, termos pensado num tablóide em papel jornal, pelo baixo custo. Ficou em papel mais encorpado e com grampos.

O projeto consumiu um ano de ponderações, lay-outs e concepção do conteúdo, quer dizer, da estrutura editorial. Começou-se pensando exclusivamente em artigos assinados e evoluiu-se para o que é: artigos e seções assinados, uma grande entrevista ou debate, reportagens e um ensaio fotográfico, basicamente.

A aceitação, embora pequena em escala, média de $17 \mathrm{mil}$ exemplares vendidos, dos 42 mil rodados, é grande em qualidade. Chega a ser comovente. Recebemos mensalmente algumas dezenas de cartas, via $e$-mail a maioria, e a maioria apaixonadas e cúmplices. Mulheres e homens, de todas as idades e regiões do Brasil, que incensam, criticam, sugerem, alguns anunciando que estão fazendo cópias das matérias e distribuindo no meio em que vivem, ou oferecendo-se para vender assinaturas ou colaborar de alguma forma. Por exemplo, este mês, uma garota de segundo ano do curso de jornalismo se propõe a ser "auxiliar do auxiliar do auxiliar...", uma maravilha! A repercussão é sensível, tanto entre estudantes quanto entre professores, entre profissionais liberais, entre religiosos, entre pessoas comuns e intelectuais, cientistas, artistas. Até entre publicitários, embora ainda estejamos carentes de anunciantes, dado vital para a vivência de qualquer publicação de banca.

\section{IMPRENSA INDEPENDENTE}

O princípio é claro, cristalino, imprensa só tem sentido quando independente. Ou não deve ser chamada de imprensa. Pode-se dar-lhe qualquer apelido, como lhe dão, mas não se pode fugir do princípio que justifica sua existência. 
Por que um homem ou um grupo funda uma empresa para fazer imprensa? Grande ou pequena, para quê? Se for para ganhar dinheiro, pura e simplesmente, não estará fazendo imprensa. Se for para ganhar poder, seria o poder de realizar um intento intelectual, a possibilidade de contribuir, nos limites que são intrínsecos à atividade, para $o$ avanço da sociedade. Não é o que se vê.

Para falar apenas da imprensa brasileira, o que vemos são as grandes empresas enveredarem por vários outros ramos, como indústria de embalagens, rótulos, hotelaria, telefonia, venda de bugigangas pela televisão etc., sem contar, no que tange à influência junto ao leitor, a intimidade suspeita e condenável com os setores administrativos do poder político e econômico (na verdade, um

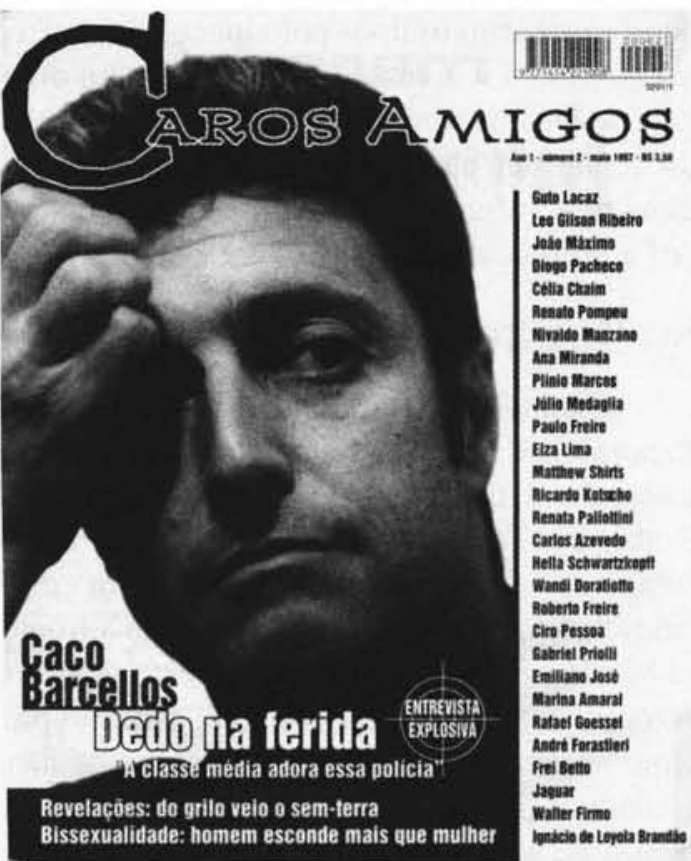

Capa da revista Caros Amigos, n 2, maio de 1997. a extensão do outro, com a desdita de, no Brasil, comporem uma só corrente). É estranhável e desconfortável não surgir no país uma empresa jornalística - vou usar o termo sem constrangimento - de esquerda. Essa unanimidade em torno do centro ou centro-direita é até compreensível, vem das origens de cada uma dessas grandes empresas jornalísticas, mas não aparecer um único editor descompromissado com a elite que se eterniza no comando administrativo (Executivo, Legislativo, Judiciário) do país é inaceitável. Faz falta até para a oxigenação das idéias.

\section{ESPAÇO COMERCIAL DE CAROS AMIGOS}

O espaço é restrito por tratar-se, principalmente, de uma revista de leitura, coisa que não tem sido cultivada pelos editores de hoje em dia. A tese predominante nos gabinetes dos executivos das grandes empresas jornalísticas brasileiras é a de que as pessoas não têm tempo para ler, preferem a informação ligeira, para não dizer superficial. Em conseqüência, com as devidas exceções, o que sai das impressoras são milhões de exemplares de revistas que reprisam o anacrônico como fazer isso ou aquilo, ou expõem a vida dos ricos e famosos. A fatuidade em primeiro lugar, num país à beira de um grave ataque de nervos. Então, voltando, o espaço da Caros Amigos é restrito, mas acredito que haja pelo menos $0,05 \%$ da população, em todos os setores de atividades, interessado no que publicamos. E sa- 
bemos que atingiríamos pelo menos essa parcela de leitores se tivéssemos recursos para divulgação. Quanto à maneira como ela se mantém: da venda em banca, venda de assinaturas, alguns poucos anúncios e da prestação de serviços editoriais a empresas.

\section{NOVAS INICIATIVAS}

Estamos prestes a lançar a Caros Amigos Reportagem, a partir de um acordo entre a nossa editora e a dirigida pelo jornalista Raimundo Rodrigues Pereira, a Oficina de Informações. Acabamos de pôr nas bancas a primeira edição nascida dessa união, um especial sobre a fronteira México-Estados Unidos, com texto de Carlos Azevedo e fotos de Sebastião Salgado. Em princípio seriam edições eventuais, mas rapidamente evoluímos para ambição maior e resolvemos que

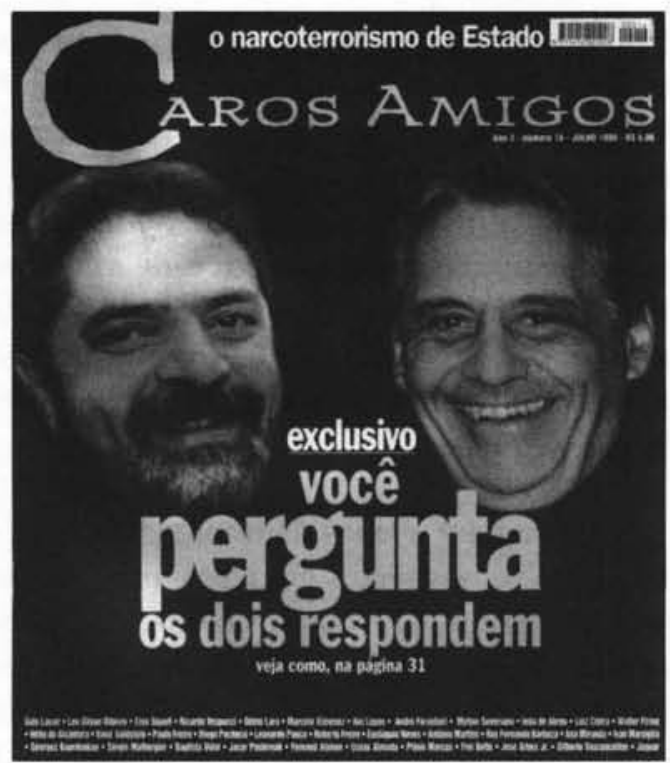

Capa da revista Caros Amigos, n 16, julho de 1998. dentro de pouco tempo a Caros Amigos Reportagem circulará também mensalmente, como acontece com a edição regular. Será uma grande reportagem por mês, realizada por profissionais de primeiro time e com matérias que, esperamos, tenham nível internacional. A próxima pauta é a China no concerto da globalização e os problemas advindos da abertura do país ao capitalismo.

Ainda em termos do futuro, devo dizer que o pessoal da Casa Amarela não tem grandes pretensões. A meta é fazer o que gostamos de fazer, ganhando para o arroz e feijão de cada um (incluindo o uísque, claro).

Resumo: O jornalista Sérgio de Souza relata, sinteticamente, sua experiência profissional, inclusive na revista Realidade, publicação da segunda metade da década de 60 , exemplo de jornalismo independente, aprofundado e crítico e, atualmente, na revista Caros Amigos, publicação mensal da qual é editor. Trata da importância da existência de uma imprensa capaz de se articular independentemente dos poderes Executivo, Legislativo e Judiciário, bem como dos interesses estritamente mercadológicos. Fala da falta que faz ao país ter uma imprensa de esquerda e também de seus projetos para o futuro com o lançamento de Caros Amigos Reportagem, resgatando o prazer da leitura de uma grande reportagem bem-feita.

Palavras-chave: Sérgio de Souza, Realidade, Caros Amigos, jornalismo, ditadura militar, reportagem
Abstract: Journalist Sérgio de Souza reports, briefly, on his experience at magazine Realidade, a publication of the late 60's - an example of independent journalism, deep and critical - and, currently at magazine Caros Amigos, a monthly publication he edits. The article deals with the importance of having a press that is capable of articulating itself independently from the Executive, Legislative and Judicial powers, as well as from the purely market-oriented interests. The article stresses what the country loses with the lack of a leftist press and it also covers Souza's projects for the future with the launching of Caros Amigos Reportagem, bringing back the pleasure of reading a well-written report.

Key words: Sérgio de Souza, Reality, Caros Amigos, journalism, military dictatorship, report 


\section{JAGUAR}

\section{Da série "Cartuns Reciclados" VALE A PENA RIR DE NOVO}

Este desenho é de 1968, foi publicado no livno $10 \mathrm{~cm}$ Humor (Editora Expressio e Cultura). quando a maioria dos leitores de Caros Amigos ainda usava fraldas. A versão original está no quadradinho ao lado. Na reciclada trinta anos depois, acrescentei uma segunda pergunta que, obviamente, teve a mesma resposta.

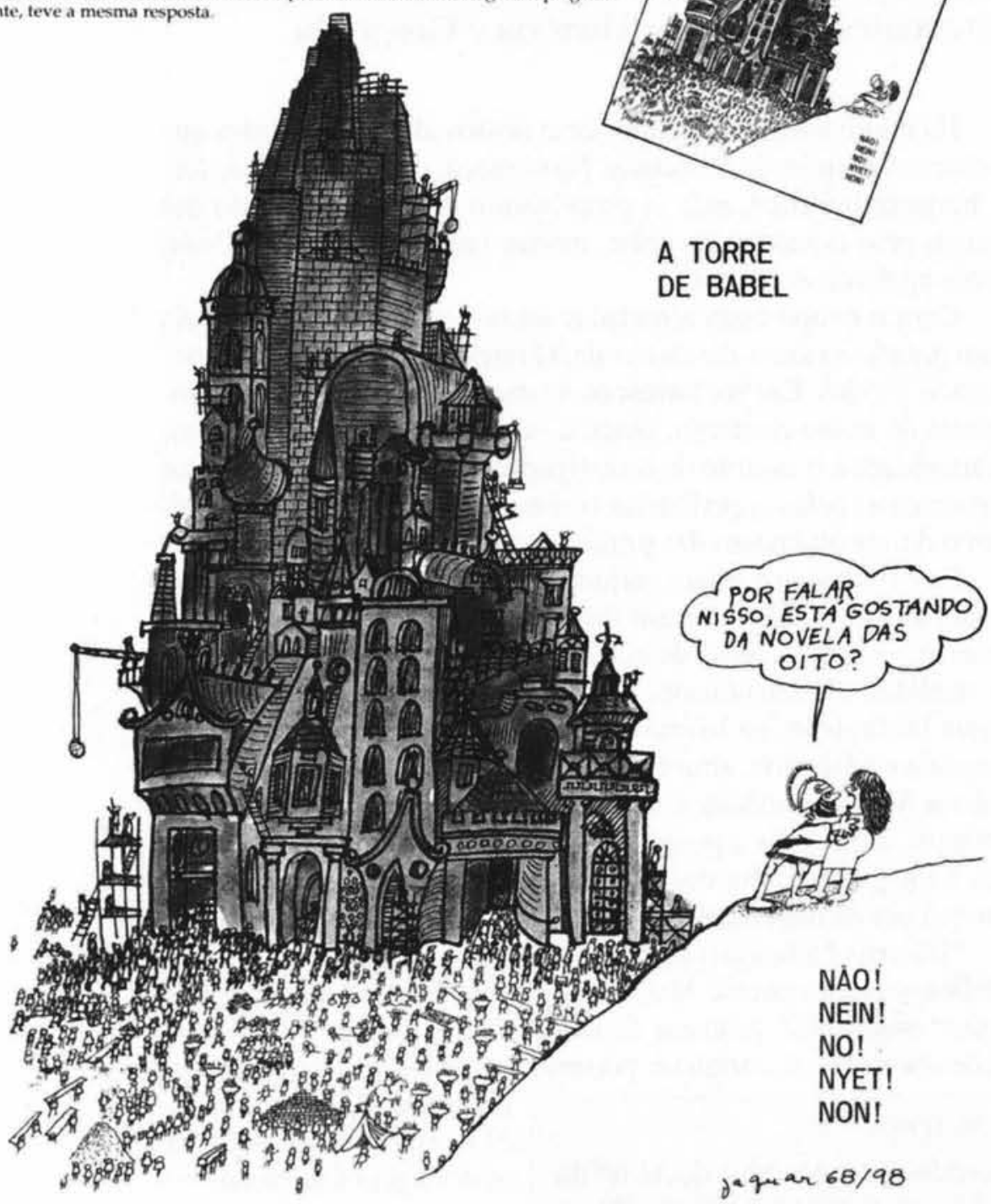

